\title{
Comunicación
}

\section{EVALUACIÓN BACTERIOLÓGICA DE SEMEN DE VERRACOS USADOS COMO REPRODUCTORES EN GRANJAS PORCINAS DE LA ZONA DE LURÍN, LIMA}

\author{
Lidia Conza B. ${ }^{1}$, Sonia Calle E. ${ }^{2,3}$, Luisa Echevarría C. ${ }^{4}$, Néstor Falcón P. ${ }^{5}$ \\ y María Cerón C. ${ }^{2}$
}

\section{AbSTRACT}

\begin{abstract}
The objective of the present study was to evaluate the bacterial content in semen from 30 healthy boars used as sires in pig farms in the coastal area of southern Lima (Lurín). Half of boars were from two technically advanced farms and the other half from one semi technically oriented farm. The gloved-hand method for semen collection was used and the collected semen was filtered to separate the gel fraction. The results indicated that in the technical farms, $73 \%$ of ejaculates (11/15) showed bacterial growth and $13 \%$ (2/ 15) exceeded the OIE limit of 5,013 UFC/ml, whereas in the non-technical farm, all ejaculates showed bacterial growth and 60\% (9/15) exceeded the OIE limit. Pseudomona aeruginosa was the bacteria with higher number of colonies per semen sample and Escherichia coli was the most common bacteria.
\end{abstract}

Key words: semen, bacterial growth, UCF

El uso de la inseminación artificial (IA) se ha incrementado en la crianza porcina contribuyendo al mejoramiento genético de los planteles de reproductores. Además, entre sus beneficios se encuentran la disminución de enfermedades por transmisión sexual y el menor número de reproductores requeridos; sin embargo, la difusión de esta tecnología depende en alguna forma de la calidad del semen colectado y procesado.
Existen muchos factores que pueden influir directamente sobre la calidad del semen porcino (García et al., 1998), entre los cuales se encuentra la contaminación por microorganismos. La contaminación bacteriana del semen ocurre habitualmente durante la colecta (Arauz et al., 2000) o puede provenir del aparato génito-urinario, pudiendo causar una disminución de la eficiencia reproductiva (Serrano et al., 1994).

\footnotetext{
${ }^{1}$ Práctica privada

${ }^{2}$ Laboratorio de Microbiología y Parasitología Veterinaria, FMV-UNMSM

${ }^{3}$ E-mail: scallee@vet.unmsm.edu.pe

${ }^{4}$ Laboratorio de Reproducción Animal, FMV-UNMSM

${ }^{5}$ Laboratorio de Medicina Veterinaria Preventiva, FMV-UNMSM
} 
Se realizó un estudio bacteriológico del semen de cerdos utilizados como reproductores en el área sur de Lima (Lurín) para determinar su condición sanitaria al servicio. Se utilizaron los cerdos reproductores de dos granjas de crianza tecnificada (animales de alta calidad genética, adecuado manejo sanitario y alimentación, instalaciones modernas y con normas de bioseguridad) y de una granja de crianza semitecnificada (parte de los reproductores eran de alta calidad genética, $\mathrm{y}$ el manejo en general, no seguía las pautas de la tecnología moderna). Los animales eran Hampshire, Belga e híbridos. Se utilizaron 15 reproductores por sistema de crianza.

Se realizaron dos colectas por animal con un intervalo de una semana usando el método de "mano enguantada". El semen fue colectado por el personal de las granjas porcinas, quienes realizaban esta actividad en forma rutinaria. El eyaculado fue colectado en un recipiente estéril, descartando la primera porción del eyaculado y filtrando la fracción de gel con gasa estéril. Las muestras fueron transportadas al Laboratorio de Bacteriología de la Facultad de Medicina Veterinaria de la Universidad Nacional Mayor de San Marcos para su procesamiento.

En la evaluación bacteriológica cualitativa de las muestras se realizaron cultivos aerobios, anaerobios y microaerófilos en agar sangre, mac conkey, tripticasa soya y salmonella-shiguella. La tipificación se realizó a través de la observación de la morfología de las colonias y de la realización de pruebas bioquímicas. Para el análisis cuantitativo de las muestras se realizó la dilución del semen y se utilizó la técnica de recuento de microorganismos presentes según el Código Zoosanitario Internacional de la OIE-2001.

El $73 \pm 22 \%$ (11/15) de los eyaculados de las dos granjas tecnificadas y todos los eyaculados (15/15) de la granja semitecnificada tuvieron desarrollo bacteriano, lo que hizo una frecuencia de $87 \pm 20 \%$.
Se encontró que el $60 \pm 25 \%$ (9/15) de los eyaculados de reproductores de la granja semitecnificada tuvo una carga bacteriana que sobrepasó las 5,013 UFC/ml (unidades formadoras de colonias), límite permitido por la OIE (OIE, 2001) en tanto que sólo el 13\% (2/15) sobrepasó este límite en los eyaculados de las dos granjas de crianza tecnificada. En general, la presencia de bacterias ocasionan efectos negativos sobre los espermatozoides al alterar el plasma seminal, constituyéndolo en una fuente de contaminación para el tracto genital de la hembra. Por otro lado, se reconoce que más de 4,000 colonias de bacterias producen una reducción de la calidad del semen y de su capacidad fertilizante (Mirjyn, 1999).

La mayor cantidad de colonias encontradas fue de la bacteria Pseudomona aeruginosa y la bacteria aislada en el mayor número de animales en ambos sistemas de crianza fue Escherichia coli. Estas bacterias han sido asociadas con alteraciones en la calidad del semen. Trabajos realizados por otros autores han demostrado el efecto espermicida de la E. coli y que además podría ser la causa de la aglutinación espermática en el eyaculado. Así mismo, la presencia de Pseudomonas está relacionada con la pérdida de motilidad espermática, reducción de la fecundación y muerte de embriones (Martínez et al., 1984). Bacterias como Proteus vulgaris, Staphylococcus aureus, Bacillus subtilis y Citrobacter sp. se encontraron en las muestras de semen sin superar los límites establecidos por la OIE. Los resultados obtenidos coinciden con reportes hechos por Sone (1990) y Tansuli et al. (1984).

\section{Literatura Citada}

1. Arauz, S; A. Stomelli; S. Williams. 2000. Estudio bacteriológico del semen porcino. Congreso Mercosur de Producción Porcina. Buenos Aires, Argentina. 
2. García, J. S. Lapuente; D. Corcuera; A. Sagüié; M. Rillo. 1998. Memorias del V Simposium Internacional de Reproducción e Inseminación Artificial en Porcinos. León, México.

3. Mirjyn, A. 1999. Stimulation and detection of heat in gilts and sows, wl flowers, tech. Report 12, NCSU.

4. Martínez, E N. Peraza; P. García. 1984. Evaluación bacteriológica de semen bovino. I. Sementales de la raza Holstein. Rev. Cub. Reprod. Anim. 10: 7-15.

5. OIE. 2001. Semen de bovinos. Código Zoosanitario Internacional. Parte 3. Tí- tulo 3.2. Anexo 3.2.1. Disponible de: http://www.oie.int.

6. Serrano, M.; M.C. Pérez; J. Miguel; J. Milán. 1994. Estudio de las anormalidades espermáticas de los verracos en relación a raza, tipo y época. Anaporc. España 139: 40-57.

7. Sone, M. 1990. Investigation on the control of bacteria in boar sperm. Jap. J. Anim. Reprod. 36: 23-29.

8. Tamuli, M. D. Sharma; C. Rajkonwar. 1984. Studies of the microbial flora of boar semen. Indian Vet. J. 61: 858-861. 